\title{
Nihonjinron: la japonización de la cultura y la sociedad
}

\section{(c) (1) (2)(2)}

Nihonjinron: the Japaneseization of culture and society

Israel A. Almeida Molina. ${ }^{1} \&$ Dra. Maria Elena Álvarez Acosta. ${ }^{2}$

Recibido: 15-06-2018 / Revisado: 19-06-2018 / Aceptado: 21-06-2018 / Publicado: 06-07-2018

Resumen. DOI: $\underline{\text { https://doi.org/10.33262/concienciadigital.v1i3.901 }}$

El presente Trabajo se enfoca en la sociedad japonesa. Se precisa analizar la situación en la que se encuentra y cómo ha sido capaz de ajustar, en su propio beneficio, sus límites culturales y mantener, así, su sentido de identidad frente a intentos de imposición. En este sentido, se destaca la tensión entre la voluntad de las industrias culturales japonesas de promoción de un producto con valores híbridos y el interés gubernamental nipón de difusión de un modelo monolítico de cultura basado en la homogeneidad e inspirado en los preceptos del nihonjinron (niponización), en una nación y sociedad donde conviven la tradición y la modernidad, en la que se incorporan y renuevan los avances de los países occidentales y que fortalece su papel en la arena internacional.

Palabras claves: Nihonjinron (niponización o japonización), cultura, sociedad, Japón.

\section{Abstract.}

This Work focuses on Japanese society. It is necessary to analyze the situation in which it is located and how it has been able to adjust, for its own benefit, its cultural limits and thus maintain its sense of identity in the face of imposition attempts. In this sense, the tension between the will of the Japanese cultural industries to promote a product with hybrid values and the Japanese interest of diffusion of a monolithic model of

\footnotetext{
1 Instituto Superior de Relaciones Internacionales "Raúl Roa García”, La Habana, Cuba, iamolina@gmail.com.

2 Instituto Superior de Relaciones Internacionales "Raúl Roa García", La Habana, Cuba, mealvarez@gmail.com.
} 
culture based on homogeneity and inspired by the precepts of nihonjinron (niponization) ), in a nation and society where tradition and modernity coexist, in which the advances of Western countries are incorporated and renewed and that strengthens their role in the international arena.

Keywords: Nihonjinron (Japanese or Japanese), culture, society, Japan.

\section{Introducción.}

Se podría suponer que la extensión y el traslado de distintas formas culturales y sociales a diferentes lugares del mundo producen, necesariamente, una homogeneización de contenidos en una cultura común, unificada e integrada. Además, las teorías acerca del imperialismo cultural y el imperialismo mediático asumen que las culturas locales son expulsadas casi a golpes de existencia, mediante la proliferación de bienes de consumo, las publicidades y los programas masivos catapultados desde el Occidente (y en gran medida desde los Estados Unidos). Pero obvian el factor tradicional y la capacidad asimiladora (y no precisamente reproductora) de las sociedades.

Derivado a estos procesos de transformación social, se inician los importantes esfuerzos realizados por los pensadores de las distintas escuelas por articular marcos teóricos y metodológicos para entender los procesos de transformación, cambio y adaptación de las sociedades, las cuales han seguido evolucionando incesantemente con el paso del tiempo. De este punto parten una serie de teóricos que analizan la forma en que visiones occidentales se han impuesto en el resto del mundo, pero que no parecen creer que las sociedades "exóticas" sean capaces de asimilar desde su tradición lo que viene desde Occidente.

En este sentido, el objetivo de este Trabajo Investigativo es explorar cómo el nihonjinron (japonización o niponización) de la cultura se comporta en el marco de las teorías globalizadoras a lo interno y lo externo de Japón.

Para ello, en el transcurso de la investigación, se emplearon tanto métodos teóricos como empíricos, con el objetivo de ponderar en todo momento la objetividad e integralidad del análisis. Asimismo, prevaleció como enfoque general, el método dialéctico-materialista.

\section{Desarrollo}

\section{Epígrafe 1 - Carácter histórico y cultural híbrido del pueblo nipón: tradición y modernidad.}

La mayoría de las teorías globalizadoras se nos muestran como autorepresentaciones de un dominador particular. Muchos de los supuestos occidentales sobre el mundo, dados por sentado, tienen un poder inmenso y su cualidad de "obviedad" no alienta la posibilidad de un diálogo. ¿Pero qué ocurre cuando encuentran resistencia? De aquí parten una serie de teóricos 
que abordan las maneras en que Occidente ha sido capaz de imponer su particular visión del "Otro exótico" en las partes más distantes del mundo. (King, 1995).

Desde el punto de vista histórico, el desarrollo de Japón posee las influencias y características más avanzadas del continente asiático primero, y de Europa y Estados Unidos después. Algunos autores explican esta ambivalencia señalando que la cultura japonesa llega a adoptar deliberadamente el marco dominante, aceptando así la falta de autenticidad en el origen, pero redefiniéndose y desmarcándose de su antecesor al facultar a dicho marco de una conciencia doméstica. (Matsui, 2007)

Luego, para entender el carácter histórico y cultural híbrido del pueblo nipón, es necesario analizar cuatro momentos claves que han marcado su evolución y su relación con el mundo:

1. Los albores de su formación local reflejada en el aislacionismo geográfico, además de la formación de su Estado y las influencias externas como moldes de su desarrollo histórico.

Debido a la cerrazón de la comunidad tribal japonesa del siglo VI, los horizontes de la sociedad eran fundamentalmente locales. En el Este del continente asiático, la cultura japonesa, aunque recibía influencias de otras civilizaciones milenarias como la India y China, alcanzó un desarrollo suigéneris; pues, por ejemplo, su situación geográfica la mantuvo protegida de conflictos que pudieran deformar su estructura de desarrollo autóctona. Este múltiple aislacionismo, influyó fundamentalmente en la formación del carácter cultural japonés. Esto se tradujo en la formación de un sistema feudal y su significado histórico en términos del desarrollo, con características propias de sus procesos socioeconómicos. (Takahashi, 1986)

2. Edo Jidai, la ruptura del orden feudal; la crisis interna; la presión extranjera y el fin del sistema Tokugawa.

Desde el siglo XVI, la influencia europea permeó la forma de vida de los japoneses, por medio de la introducción de ideas cristianas de las misiones católicas provenientes de Portugal y España particularmente. Sin embargo, para 1639 la mayoría de los occidentales fueron expulsados por el Shogunato de Tokugawai. Las razones no fueron de corte religioso esencialmente, sino comercial ya que los occidentales representaban una competencia para los daimyos.

En el periodo Edo (1603-1868), se estructuran muchos de los rasgos que conforman la sociedad japonesa actual, es decir: su modo de pensar, su escala de valores, su conducta social y sus instituciones públicas. Prueba de esto es la segmentación del tejido social en: la clase gobernante samurái, la agrícola y la ciudadana (artesanos, mercaderes y comerciantes). Todo esto se da previo a su apertura paulatina hacia el exterior en el año 1854 con la firma del tratado de Kanagawa que se hace efectivo en su totalidad en la época Meiji. (Gordon, 2003) 
3. La época Meiji como restauración del poder imperial y la renovación de las estructuras sociales como antesala del expansionismo japonés de finales del siglo XIX y principios del XX.

El proceso de modernización política de Japón se dio mucho más acelerado que en Europa occidental. A principios de 1870, el gobierno comenzó a abolir las estructuras remanentes del feudalismo. De la misma manera, el viejo sistema administrativo se modificó.

La renovación Meiji (1868-1912) presentó cambios significativos en lo social y económico. Se caracterizó por la creación de estructuras militares y constitucionales, así como por una política exterior modelada, en la práctica, por Europa y los Estados Unidos de finales del siglo XIX. Por su parte, el gobierno proveyó la infraestructura necesaria en la banca, transporte, comunicaciones, sistema de educación y sistema de leyes para la modernización del país. Un factor que sobresale en este periodo es la contratación por parte del Gobierno japonés de expertos extranjeros (en casi todas las áreas) con el objetivo de introducir conocimiento y técnicas de otros países avanzados, una doctrina que se desarrolló con el nombre de conocimiento universal y que influyó definitivamente en cómo la cultura japonesa comenzó a adaptar en su estructura los patrones occidentales, pero sin perder su esencia. (Muto, 1996).

En este período, Japón se benefició de la ventaja de su alianza estratégica con las potencias capitalistas occidentales que buscaban consolidarse como hegemones en el área. Las implicaciones económicas se ven reflejadas en la transformación de Japón en un gran país industrial y rápidamente, en su evolución imperialista.

En esta época de auge económico y vertiginosa modernización industrial, Japón aprendía de Occidente, al tiempo que competía con este por los mercados más importantes del mundo. El surgimiento de los zaibatsuz y la expansión de la influencia comercial japonesa, proyectaron hacia lo interno y al exterior de Japón una imagen que comenzó a rivalizar con los patrones económicos y culturales supremacistas que promovían los países occidentales.

En esencia, fue su tradición aislacionista, su vertiginosa entrada en el mundo monopolista y su rápido ascenso como poder dominante en el área, los que propiciaron la conformación y cristalización de un nacionalismo con carácter expansionista que repelía la influencia de poderes externos en un área que fue considerada como "el espacio vital" del imperio japonés. (Maruyama, 1969).

4. El Militarismo, la Segunda Guerra Mundial y la Posguerra.

El auge del militarismo japonés ocurre en un nuevo escenario de alianzas con Occidente. El ascenso de Alemania en la arena económica y política internacional, la competencia económica y geopolítica con la URSS, los resultados de la invasión japonesa a Manchuria en 1932 con la expulsión de Japón de la Liga de las Naciones, determinaron en gran medida que 
el militarismo japonés integrara concepciones del modelo alemán en sus dinámicas de producción y desarrollo, apoyando a las industrias estratégicas, en donde figuraban las dedicadas a la producción armamentista.

Es entonces que se produce la segunda guerra mundial. Momento de inflexión en nuestro análisis.

La derrota de Japón en el conflicto, la manera en que experimentó el arma más destructiva en la historia de la humanidad, el modo en que la rendición de su Estado fue sentenciado por el emperador, y la manera en la que el territorio fue ocupado por los Estados Unidosiii, conformaron el proceso de cambio más radical en la mentalidad y forma de vida japonesas. Sin embargo, las transformaciones encontraron, una vez más, una base sólida de tradiciones que no pudieron ser desarticuladas. (Togores Sánchez, 2000)

\section{Epígrafe 2 - La japonización entre las teorías globalizadoras. Universalización y trivialización de la cultura japonesa en Occidente}

El resultado de este proceso es un movimiento multicultural que acepta y promueve la intercomunicación con otras culturas a través de la globalización y que, sin dejar de lado la tradición, apuesta por manifestaciones lejanas a la caracterización de la sociedad japonesa como una sociedad única y homogénea. En este sentido, resulta interesante señalar la evidente tensión entre la voluntad de las industrias culturales japonesas de promoción de un producto con valores híbridos y el interés gubernamental nipón de difusión de un modelo monolítico de cultura, basado en la homogeneidad, e inspirado en los preceptos del nihonjinron (niponización).

Esto tal vez sugiera que el contraste sociológico de base entre tradición y modernidad no resulta tan útil, pues no puede ser analizado con facilidad en la presunta lógica de desarrollo de la modernización. Pero eso sería caer nuevamente en una mirada Occidental del fenómeno. En efecto, se sabe que Japón se las ingenió para un imponer un proyecto particularista de modernidad y que ha sido capaz de protegerlo en contra de los desafíos universalistas. Lo anterior nos revela la persistente importancia de los factores culturales en el desarrollo de los estados-nación, pero también de cómo esto influirá en sus relaciones con otros estadosnación. (Sakai, 1989)

En este sentido, es insuficiente asumir que las culturas no occidentales cederán, simplemente, ante la lógica inexorable de la modernidad y que adoptarán formas occidentales. Asimismo, no es razonable concebir las formulaciones de particularidad nacional como meras reacciones de respuesta ante la modernidad occidental. Es decir, la japonización, ya sea desde el punto de vista histórico o sociológico, es más que una respuesta o una reacción ante la occidentalización. 
Este es precisamente uno de los problemas que aparece al intentar formular una teoría acerca de la japonización, el de adoptar una lógica totalizante y asumir que un proceso maestro de integración global está en marcha, que devorará al resto y tornará al mundo en un ámbito más unificado y homogéneo.

Pero Japón, como imagen universal y experiencia vicarial, ha demostrado lo opuesto. Dicha imagen se ha copiado e implementado en muchísimas de las facetas de la cotidianidad, dependiendo centralmente de la concepción de un imaginario que no se alimenta de la experiencia real, aunque fuese mínima, pues responde en forma exclusiva a la oferta mediática de anime, películas, literatura, fotografías o simples referencias que van a parar, no al acervo informacional que busca una organización racional (como el conocimiento escolarizado) para su investigación posterior, sino a la colección de sentimientos y construcciones ideales.

Lo anterior se traduce en un Asia que está de moda en Occidente. Lo japonés se destila y vende bien, en tanto se asiste a una trivialización de su cultura en el mercadoiv: champú zen, ceniceros que son jardines secos en miniatura, budas transparentes, una fascinación inusitada por la soja o prendas de vestir con garabatos que pretenden hacerse pasar por caracteres japoneses y que desde luego no existen en Asia Oriental.

Frente a este escenario, la sociedad japonesa, como todas las sociedades del mundo desarrollado, baila al ritmo que marca la globalización, pero con su propio estilo: no por ello desaparece su idiosincrasia. Más bien poco a poco van modificándose los antiguos usos y sin violencia ni esfuerzo adapta, el pueblo japonés, al medio en el que vive. (Morris-Suzuki, 2008)

Japón ha mantenido desde esa instancia a la actualidad un modelo de estado confuciano y una sociedad donde conviven la tradición y la modernidad, incorporando y renovando los avances de los países occidentales y apoyándose en el poder de sus aliados estratégicos para fortalecer su papel en la arena internacional. De manera general, es uno de los pocos países que ha logrado aprender y aprehender las lecciones de su pasado y aprovechar, como en el judo, la fuerza de sus oponentes para compensar sus debilidades.

Precisamente, el nihonjinron surgió de la búsqueda identitaria y de análisis del pueblo japonés, pero fue usado como herramienta nacionalista. Después de la derrota en la Segunda Guerra Mundial, sin embargo, se alzó como herramienta del nacionalismo más benigno (y no militarista) y se centró en el objetivo de responder a la pregunta "quién son los japoneses" para destacar aquellos conceptos que diferencian al pueblo japonés del resto de pueblos y países y que por lo tanto lo hacen único y singular.

$\mathrm{Y}$ aunque es increíblemente interesante leer las explicaciones de conceptos como el amae o dependencia, la organización grupal, las dualidades de tatemae- honne y uchi-soto, lo cierto 
es que no podemos perdernos en estas descripciones. Nihonjinron debería ser una herramienta para extraer los conceptos básicos de la sociedad japonesa y no tanto como una demostración de la singularidad, homogeneidad o, especialmente, superioridad del pueblo japonés.

Leer estudios sobre la teoría nihonjinron es profundamente enriquecedor para conocer las características del pueblo japonés. Pero siempre requerirá de nosotros, como externos, una visión objetiva de nuestras propias sociedades, grupos y características.

\section{Conclusiones}

- El Nihonjinron, no puede ser visto exclusivamente como un proceso reactivo ante el avance de la occidentalización. Esto solo equivaldría a negar la originalidad de la cultura milenaria japonesa y de su adaptación continua, tanto a su ambiente natural y posición geográfica, como a los complejos procesos socioeconómicos y políticos que han caracterizado su devenir histórico, desde mucho antes de su contacto con Occidente.

- La japonización como proceso sociológico, se encuentra profundamente arraigado en la sociedad nipona desde sus orígenes, la cual ha logrado asimilar para sí, acorde a cada época histórica y al desarrollo de sus fuerzas productivas, los avances técnicos y científicos más novedosos, primero de Asia, y luego de Europa y Estados Unidos. Pero dicha asimilación no significó, de ninguna manera, reproducción o calco; sino más bien, comprensión, inspiración, apropiación y creación de un producto totalmente original, afín a la realidad japonesa.

- Los actuales Estado, Nación y sociedad japonesa, inmersos en un mundo globalizado, se han colocado entre las potencias económicas más poderosas del sistema internacional y han desarrollado un capitalismo monopolista sui géneris. Sin embargo, es en su desarrollo, con el avance de los monopolios culturales y comerciales, que la modernidad y la tradición que han unido su cultura enfrentan la dicotomía que podría amenazar su complementariedad: la tensión entre la voluntad de las industrias culturales japonesas que promueven un producto con valores híbridos, y el interés del gobierno japonés, que 
pretende difundir un modelo monolítico de cultura basado en la homogeneidad e inspirado en los preceptos del nihonjinron (niponización).

\section{Referencias bibliográficas.}

Arnason, J. (1990). Nationalism, globalization and modernity. Londres: Global Culture.

Azuma, H. (11 de febrero de 2014). Superflat Japanese Postmodernity. Obtenido de Superflat: www.hirokiazuma.com

Barlés, E., \& Almazán, D. (2010). Japón y el mundo actual. Zaragoza: Prensas Universitarias de Zaragoza.

Bonifazi, M. (8 de Junio de 2010). Japón: Revolución, occidentalización y milagro económico. Obtenido de Observatrio de Conflictos: http://www.nodo50.org/observatorio

Goodman, R. (2012). Family and Social Policy in Japan: Anthropological Approache. Cambridge: Cambridge University Press.

Gordon, A. (2003). A Modern History of Japan: From Tokugawa Times to the Present. Nueva York: Oxford University Press.

King, A. D. (1995). The times and spaces of modernity (or who needs postmodernism?). Londres: Global Modernities.

Laborde Carranco, A. A. (29 de Enero de 2011). Japón: una revisión histórica de su origen para comprender sus retos actuales en el contexto internacional. Obtenidode En Claves de Pensamiento: http://www.scielo.org.mx/pdf/enclav/v5n9/v5n9a7.pdf

Lu, D. J. (2007). Japan, a Documentary History. Nueva York: An East Gate Book.

Maruyama, M. (1969). Thought and Behavior in Japanese Politics. Londres: Oxford University Press. 
Matsui, M. (2007). Murakami Matrix: Takashi Murakami’s Instrumentalization of Japanese Postmodern Culture. Los Angeles: Paul Schimmel: Museum of Contemporary Art.

Mitsuhiro, Y. (1989). Postmodernism and mass images in Japan. Sapporo: Public Culture.

Morris-Suzuki, T. (2008). Cultura, Etnicidad y Globalización: La experiencia Japonesa. México: Siglo Veintiuno.

Muto, I. (1996). Lucha de clases e innovación tecnológica en Japón. Barcelona: Antídoto.

Sakai, N. (1989). Modernity and its critique: the problem of universalism and particularism. Durham: Duke University Press.

Takahashi, K. (1986). Del Feudalismo al Capitalismo. Barcelona: Crítica.

Togores Sánchez, L. E. (14 de Junio de 2000). Japón en el siglo XX: de imperio militar a potencia económica. Obtenido de La Casa del Libro: https://www.casadellibro.com/libro-japon-en-el-siglo-xx-de-imperiomilitar-a-potencia-economica/9788476354100/704318.

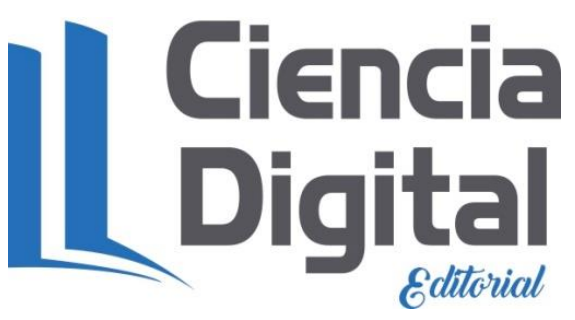


Para citar el artículo indexado.

Almeida Molina, I. A., \& Álvarez Acosta, M. (2018). Nihonjinron: la japonización de la cultura y la sociedad. ConcienciaDigital, 1(3), 63-72.

https://doi.org/10.33262/concienciadigital.v1i3.901

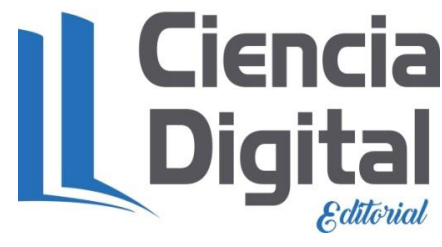

El artículo que se publica es de exclusiva responsabilidad de los autores y no necesariamente reflejan el pensamiento de la Revista Conciencia Digital.

El articulo queda en propiedad de la revista y, por tanto, su publicación parcial y/o total en otro medio tiene que ser autorizado por el director de la Revista Conciencia Digital.
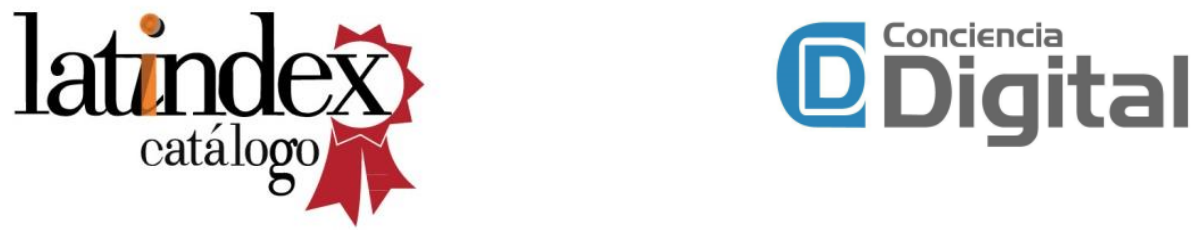